\title{
Ethylene Response Factor 1 Mediates Arabidopsis Resistance to the Soilborne Fungus Fusarium oxysporum
}

\author{
Marta Berrocal-Lobo and Antonio Molina \\ Laboratorio de Bioquímica y Biología Molecular, Departamento de Biotecnología-UPM, ETS Ingenieros Agrónomos, Avda. \\ Complutense, E-28040 Madrid, Spain
}

Submitted 2 December 2003. Accepted 4 February 2004.

\begin{abstract}
Ethylene response factor 1 (ERF1) is a transcriptional factor from Arabidopsis thaliana that regulates plant resistance to the necrotrophic fungi Botrytis cinerea and Plectosphaerella cucumerina and whose overexpression enhances resistance to these fungi. Here, we show that ERF1 also mediates Arabidopsis resistance to the soilborne fungi Fusarium oxysporum sp. conglutinans and $F$. oxysporum f. sp. lycopersici, because its constitutive expression in Arabidopsis confers enhanced resistance to these pathogens. Expression of ERF1 was upregulated after inoculation with $F$. oxysporum f. sp. conglutinans, and this response was blocked in ein2-5 and coil-1 mutants, impaired in the ethylene (ET) and jasmonic acid (JA) signal pathways, respectively, which further indicates that ERF1 is a downstream component of $\mathrm{ET}$ and $\mathrm{JA}$ defense responses. The signal transduction network controlling resistance to $F$. oxysporum fungi was explored using signalingdefective mutants in ET (ein2-5), JA (jar1-1), and salicylic acid (SA) (NahG, sid2-1, eds5-1, npr1-1, pad4-1, eds1-1, and pad2-1) transduction pathways. This analysis revealed that Arabidopsis resistance to $F$. oxysporum requires the ET, JA, and SA signaling pathways and the NPR1 gene, although it is independent of the PAD4 and EDS1 functions.
\end{abstract}

Additional keywords: EREBP, plant defense, signal transduction pathways.

Plants defend themselves from pathogens by a complex array of mechanisms, which are either constitutive or activated upon pathogen recognition (Glazebrook 2001; Holt et al. 2003). The accumulated evidence shows that plants, like other living organisms, have the ability to discriminate between self and nonself, and to specifically recognize molecular patterns from the different types of pathogens. This allows plants to mount appropriate defense responses to restrict invasion by pathogens (Dangl and Jones 2001; Holt et al. 2003; Nürnberger and Scheel 2001).

The role of the signal transduction pathways mediated by the phytohormones salicylic acid (SA), ethylene (ET), and jasmonic acid (JA) in the activation of plant defense responses against pathogens is well established (Dong 1998; Glazebrook 2001; Thomma et al. 2001). SA plays a relevant function in gene-for-gene resistance and in systemic acquired resistance (SAR) (Dempsey et al. 1999; Ryals et al. 1996). Treatment with exogenous SA activates defense genes, such as $P R-1$, and en-

Corresponding author: A. Molina; Telephone: 34-913365698; Fax: 34-913365757; E-mail: molina@bit.etsia.upm.es

Current address of M. Berrocal-Lobo: Carnegie Institution of Washington, Dept. Plant Biology, 260 Panama St., Stanford, CA 94305, U.S.A. hances resistance to various pathogens (Dempsey et al. 1999; Ryals et al. 1996). Furthermore, depletion of SA, either by transgenic expression of the bacterial $N a h G$ gene or by inactivation of enzymes involved in SA biosynthesis, as it occurs in the sid2 or eds 5 mutants, breaks gene-for-gene resistance and SAR, and enhances susceptibility to virulent pathogens, such as the bacterium Pseudomonas syringae, the biotrophic oomycete Peronospora parasitica, and the necrotrophic fungus Plectosphaerella cucumerina (Berrocal-Lobo et al. 2002a; Delaney et al. 1994; Nawrath et al. 2002; Nawrath and Métraux 1999; Wildermuth et al. 2001).

Arabidopsis mutants defective in SA-signaling that show enhanced susceptibility phenotypes, such as pad4, eds 1 , and nprl, also have been characterized (Glazebrook 2001). PAD4 and $E D S 1$ act upstream of SA to promote SA accumulation and are required for the resistance mediated by genes of the toll-interleukin-receptor (TIR) subclass of nucleotide-bindingsite (NBS) leucine-rich-repeat (LRR) resistance genes (Aarts et al. 1998; Falk et al. 1999; Glazebrook et al. 1997; Jirage et al. 1999). NPR1 is required for SAR activation and SA responses, and it is involved in regulation of defense gene expression (e.g., $P R-1$ ) through the alteration of the activity of TGA transcriptional factors (Cao et al. 1997; Fan and Dong 2002; Ryals et al. 1997).

The ET and JA signaling pathways regulate several physiological processes, including plant resistance to pathogens and activation of rhizobacteria-mediated induced systemic resistance (ISR) (Pieterse and van Loon 1999; Turner et al. 2002; Wang et al. 2002). Exogenous application of JA and ET synergistically induces defense genes, such as $P R-1 b$ and $P D F 1.2$ (Penninckx et al. 1996; Xu et al. 1994), and JA treatment confers resistance to necrotrophic fungi, such as Botrytis cinerea and P. cucumerina (Thomma et al. 2000). Moreover, impairment of the JA pathway, as it occurs in the coil or jarl mutants, or of ET signaling, as it happens in mutant ein2, increases Arabidopsis susceptibility to these fungi as well as to other bacterial and fungal pathogens (Berrocal-Lobo et al. 2002a; Clarke et al. 2000; Ellis et al. 2002; Geraats, et al. 2002; Hoffman et al. 1999; Knoester et al. 1998; NormanSetterblad et al. 2000; Staswick et al. 1998; Thomma et al. 1998, 2000; Vijayan et al. 1998).

The role of the ET and JA signaling pathways in plant defense also is supported by the demonstration that overexpression of the ethylene response factor 1 (ERF1) in Arabidopsis confers enhanced resistance to $B$. cinerea and $P$. cucumerina (Berrocal-Lobo et al. 2002a). The transcriptional factor ERF1, which belongs to the APETALA/ethylene-responsive-elementbinding protein (EREBP) family (Singh et al. 2002), has been proposed to be an integrator of ET and JA defense responses (Lorenzo et al. 2003). Expression of ERF1 is induced by treat- 
ment with ET or JA, and this response requires both a functional ET and JA pathway and, thus, is blocked in ein2 and coil mutants (Lorenzo et al. 2003; Solano et al. 1998). Consistent with its proposed defensive function, ERF1 is also upregulated after infection with B. cinerea or Pseudomonas syringae, and its induction depends on ET and ET plus JA signaling, respectively, whereas it is SA independent (Berrocal-Lobo et al. 2002a; Chen et al. 2002; Oñate-Sánchez and Singh 2002).

Increasing evidence indicates that the ET and JA pathways may be relevant for plant resistance to soilborne fungi and oomycetes present in soils, which infect plants through the roots, leading to stem necrosis. Arabidopsis mutants impaired in the JA and ET pathways show enhanced susceptibility to several Pythium spp. isolates, and tobacco plants insensitive to ET are susceptible to several soilborne pathogens such as Rhizoctonia solani, Pythium spp., Rhizopus stolonifer, Fusarium solani, and F. oxysporum (Geraats et al. 2002; Hoffman et al. 1999; Knoester et al. 1998). The fungus $F$. oxysporum, a species that includes more than 120 formae speciales classified on the basis of host specificity (Armstrong and Armstrong 1981), is the causal agent of Fusarium wilt disease, which affects many agricultural and floricultural crops (Beckman 1987). Plant germ plasm sources for suitable resistance to Fusarium wilt disease are not always available although, in some $F$. oxysporum-plant interactions, gene-for-gene resistance has been described and the corresponding gene identified (Simons et al. 1998).

Several Fusarium spp. fungi have been shown to infect Arabidopsis plants (Mauch-Mani and Slusarenko 1994; Pieterse et al. 1998; Urban et al. 2002), but the genetic basis and molecular mechanisms that control resistance to these fungi remain poorly understood. To facilitate plant colonization, some Fusarium spp., like some necrotrophic fungi, synthesize a wide range of phytotoxic compounds (e.g., fumonisin B1) which induce a programmed-cell-death (PCD) similar to that of the hypersensitive reaction elicited by an avirulent pathogen (Asai et al. 2000; Stone et al. 2000).

To extend the characterization of ERF1 function in plant defense mechanisms and to determine the signaling transduction network controlling plant resistance to $F$. oxysporum soilborne fungi, we have explored the interaction between Arabidopsis and $F$. oxysporum f. sp. conglutinans and $F$. oxysporum f. sp. lycopersici. Here, we show that ERF1 mediates plant resistance to these fungi, because its constitutive expression in Arabidopsis is sufficient to confer enhanced resistance to them, and we demonstrate that Arabidopsis resistance to F. oxysporum is complex and requires intact ET, JA, and SA signaling pathways. Furthermore, we provide data that supports the function of ERF1 as a key integrator of ET and JA defense responses.

\section{RESULTS}

Induction of ERF1 upon infection with $F$. oxysporum f. sp. conglutinans depends on ET and JA pathways and is SA independent.

The involvement of ERF1 in Arabidopsis resistance to the necrotrophic fungi $B$. cinerea and Plectosphaerella cucumerina (Berrocal-lobo et al. 2002a) prompted us to characterize ERF1 function in plant defense against other pathogens, and in particular in that against the soilborne fungus $F$. oxysporum f. sp. conglutinans, which was found to infect Arabidopsis plants. To this end, 10-day-old plants, growing on Murashige and Skoog (MS) agar plates, were inoculated with a spore suspension $(5 \times$ $\left.10^{5} \mathrm{spores} / \mathrm{ml}\right)$. Under the test conditions, infection proceeded through the roots and then affected vascular tissue, causing the following disease symptoms: root growth inhibition, plant size reduction, anthocyanins accumulation, and chlorosis and necrosis of the cotyledons, eventually leading to wilting and decay of the plant. These symptoms were similar to those observed when
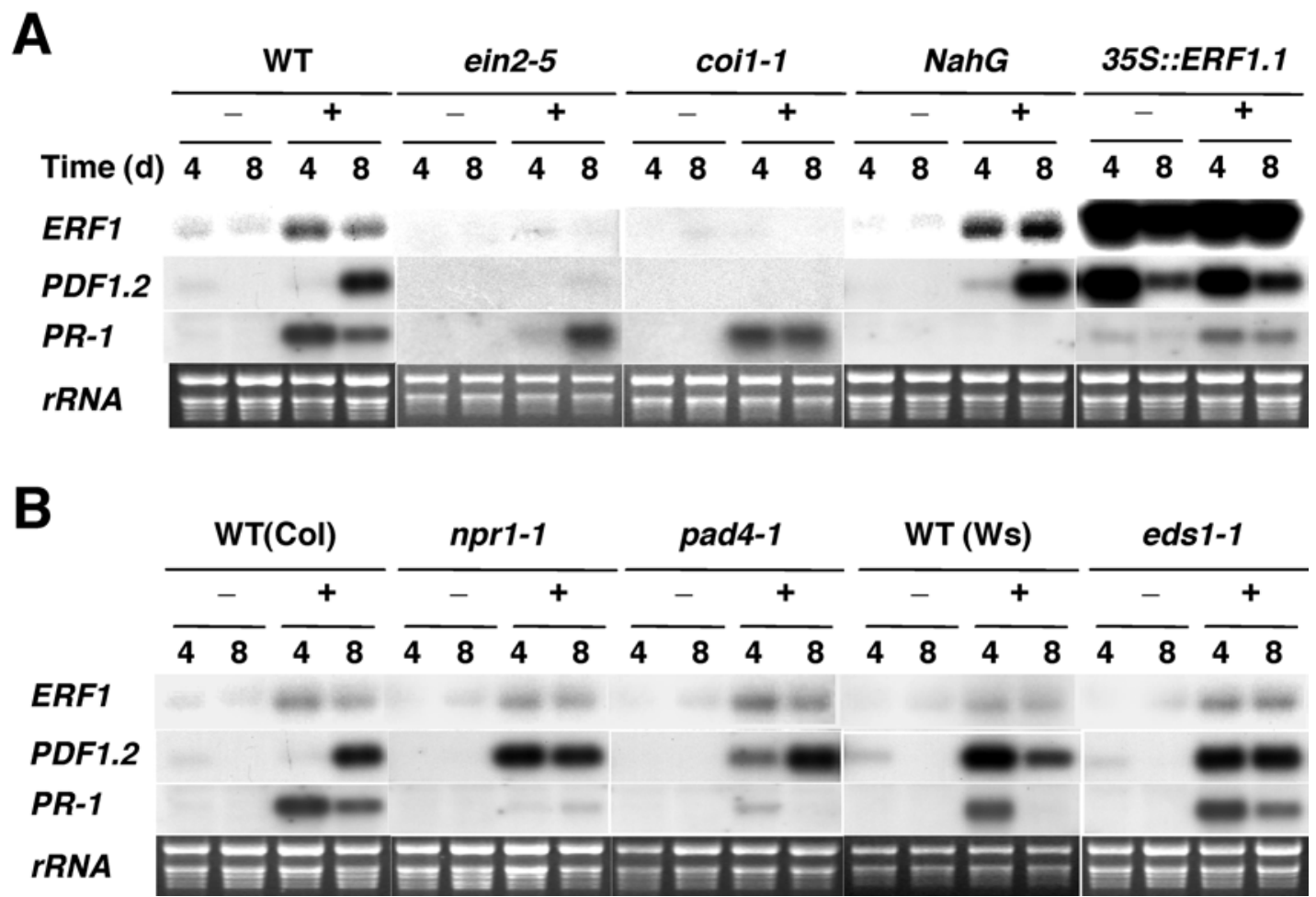

Fig. 1. Northern blot analysis of the induction of ethylene response factor 1 (ERF1) expression after Arabidopsis thaliana infection with Fusarium oxysporum f. sp. conglutinans. Total RNA ( $5 \mu \mathrm{g}$ per lane) from plants collected at different days (d) after mock inoculation $(-)$ or inoculation (+) with a spore suspension $\left(5 \times 10^{5}\right.$ spores/ml). A, Wild-type (WT) (Col-0) plants, ein2-5, and coil-1 mutants, NahG plants, and line ERF1 (35S::ERF1.1). B, WT (Col-0, and Ws-0) plants, and npr1-1, pad4-1, and eds1-1 (in Ws-O background) mutants. The blots were hybridized with the indicated probes. Ethidium bromide-stained $r R N A$ is included as loading control. 
plants growing on soil were drenched with a spore suspension of the fungus (data not shown).

Under the above conditions, we investigated whether the ERFl gene, as well as the signaling network controlling this expected response, responded to the infection. Wild-type (WT) plants, mutants impaired in the ET (ein2-5), JA (coil-1), or SA $(N a h G)$ signaling pathways, and plants from one representative overexpressing the ERF1 transgenic line (35S::ERF1), were tested. Total RNA was isolated from whole plants 4 and 8 days after inoculation, and the expression of ERF1 was analyzed by Northern-blot. ERF1 expression was induced in WT and NahG plants, but not in the ein2-5 and coil-1 mutants (Fig. 1A). The enhanced ERFI induction in the NahG plants compared with WT plants may be the result of the faster progression and higher level of fungal infection in the NahG plants (Figs. 1A and 2). These results indicate that ERF1 response to this fungus is ET and JA dependent and SA independent.

To confirm that ERF1 induction by this fungus does not depend on SA signaling, gene expression upon infection was analyzed in several SA-defective mutants: nprl-1, which is blocked in SA signaling downstream of SA accumulation (Cao et al. 1996; Ryals et al. 1997), and pad4-1 and eds 1-1, which are blocked in the SA pathway upstream of SA synthesis (Falk et al. 1999; Jirage et al. 1999). Ten-day-old plants from ecotypes Col-0 and Ws-0, nprl-1 and pad4- 1 (Col-0 background), and eds $1-1$ (Ws-0 background) were inoculated with the fungus. Total RNA from whole plants was extracted 4 and 8 days after inoculation and ERF1 expression was analyzed by Northern blot. ERF1 response to the fungus was similar in the mutants and the WT plants, further indicating that it does not depend either on the NPRI and EDS1 genes, or on PAD4 gene that has been suggested to repress the SA-induced expression of ERF1 and other specific ERF genes (Fig. 1B) (Oñate-Sánchez and Singh, 2002).

The expression patterns of the defense genes PDF1.2 and $P R-1$ after $F$. oxysporum $\mathrm{f}$. sp. conglutinans inoculation also were determined. Although both genes were upregulated by fungal infection in WT plants, $P D F 1.2$ induction was reduced or completely blocked in the ein2-5 and coil-1 mutants, and $P R-1$ upregulation was weaker in NahG, nprl-1, and pad4-1 plants (Fig. 1A and B). In the 35S::ERF1 transgenic line used as control, $P D F 1.2$ was constitutively expressed in mock and infected plants and the expression of $P R-1$ was induced upon fungal infection, but this upregulation was weaker than that observed in WT plants and might reflect the lower level of infection of the transgenic plants compared with WT plants (Figs. 1B and 2). Induction of ERF 1 by $F$. oxysporum f. sp. conglutinans infection preceded the upregulation of its target gene PDF1.2 (Fig. 1B), as has been described after B. cinerea infection (Berrocal-Lobo et al. 2002a).

\section{Overexpression of $E R F 1$ confers enhanced resistance \\ to $F$. oxysporum f. sp. conglutinans}

and $F$. oxysporum f. sp. lycopersici.

The upregulation of ERF1 by $F$. oxysporum f. sp. conglutinans infection and the enhanced resistance to $B$.

Fig. 2. Plant fresh weight (FW) reduction (\%; average \pm standard deviation) and disease symptoms caused by Fusarium oxysporum f. sp. conglutinans. A, FW reduction in wild-type (WT) (Col-0 and Ws-0), transgenic lines 35S::ERF1.1 and 35S::ERF1.2, and mutants ein2-5, jar1-1, NahG, npr1-1, pad4-1, and eds $1-1$ (Ws-0 background), 10 days after inoculation with $5 \times$ $10^{5}$ spores $/ \mathrm{ml}$. Asterisks indicate data significantly different from the corresponding WT data set $(P>0.95, t$ test). B, Disease sympytoms and $\mathbf{C}$, lactophenol trypan blue staining of WT (Col-0), 35S::ERF1, and NahG plants 10 days after inoculation. Arrows indicate necrotic tissue areas. cinerea and $P$. cucumerina of plants that overexpress ERF1 (Berrocal-Lobo et al. 2002a) prompted us to analyze whether these plants also were more resistant than WT plants to $F$. oxysporum f. sp. conglutinans. Ten-day-old WT and ERF1-

A
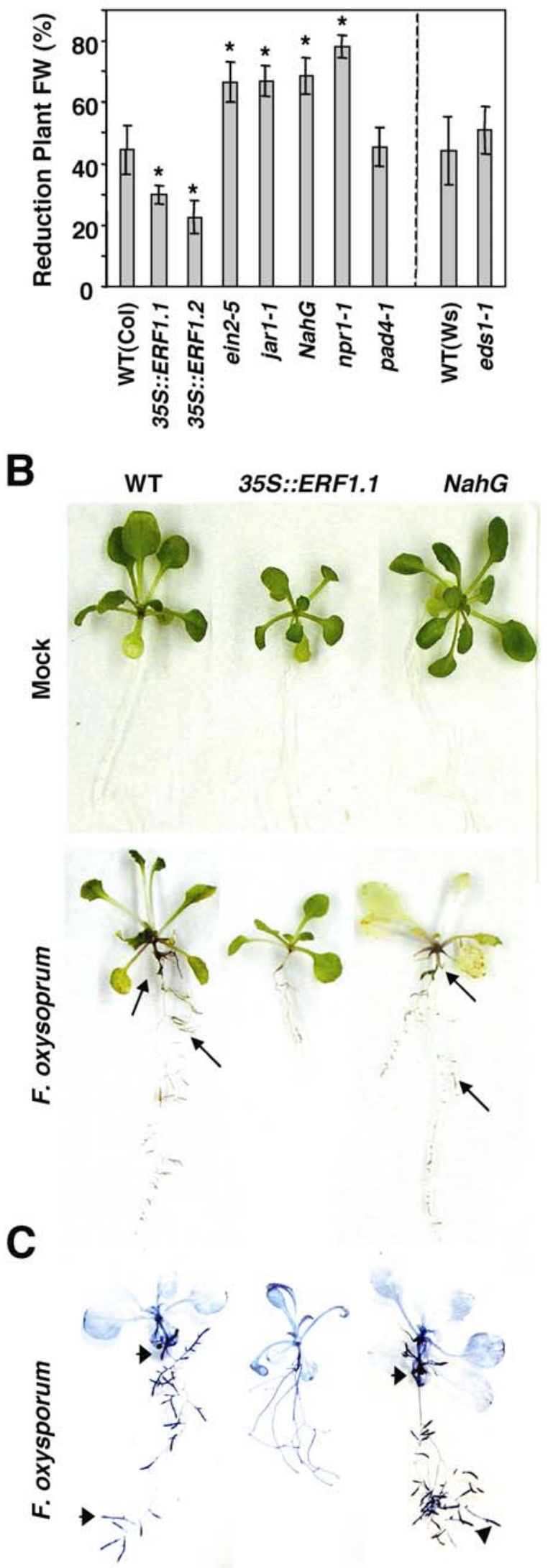
transgenic plants (lines 35S::ERF1-1 and 35S::ERF1-2), growing on MS agar plates, were inoculated with a spore suspension. After 10 days, the level of infection was quantified as the percentage of fresh weight (FW) reduction caused by the fungus, which correlated with the severity of macroscopic disease symptoms. FW reduction in the inoculated ERF1 transgenic lines was significantly lower (20 to 30\%) than that in the WT plants $(42 \%)$, indicating that $E R F 1$ overexpression was sufficient to confer enhanced resistance to this fungus (Fig. 2A). In WT plants, 10 days after inoculation, stems and lateral roots were necrotic, leaves were chlorotic, and wilting was visible, whereas macroscopic disease symptoms were not detectable in the resistant $35 S:: E R F 1$ plants, which, as described previously (Solano et al. 1998), showed a dwarf phenotype (Fig. 2B and data not shown). Trypan blue staining of inoculated plants revealed that necrotic cells were abundant in stems and lateral roots of the WT plants and scarce in the ERF1 transgenic plants (Fig. 2C).

To determine whether the observed enhanced resistance of the $35 S:: E R F 1$ plants was restricted to $F$. oxysporum f. sp. conglutinans or had a broader $F$. oxysporum spectrum, we analyzed their resistance to the tomato fungal pathogen $F$. oxysporum f. sp. lycopersici (Di Pietro and Roncero 1996), which also infected Arabidopsis, causing disease symptoms similar to those produced by $F$. oxysporum $\mathrm{f}$. sp. conglutinans, though less severe. Ten-day-old WT, 35S::ERF1-1, and 35S::ERF1-2 plants growing on MS agar plates were inoculated with a spore suspension $\left(5 \times 10^{5}\right.$ spores $\left./ \mathrm{ml}\right)$ and reduction of plant $\mathrm{FW}$ was determined 10 days later. FW reduction in the inoculated $35 S: \because E R F 1$ plants was significantly lower (7 to $15 \%)$ than that in the WT plants (32\%) (Fig. 3). These results indicate that overexpression of ERF1 in Arabidopsis is sufficient to confer enhanced resistance to several $F$. oxysporum fungi and suggest a relevant function of ERF1 in resistance to these soilborne fungi.

\section{Signal transduction network controlling}

Arabidopsis resistance to $F$. oxysporum.

To characterize the signal transduction network controlling Arabidopsis resistance to $F$. oxysporum fungi, 10-day-old

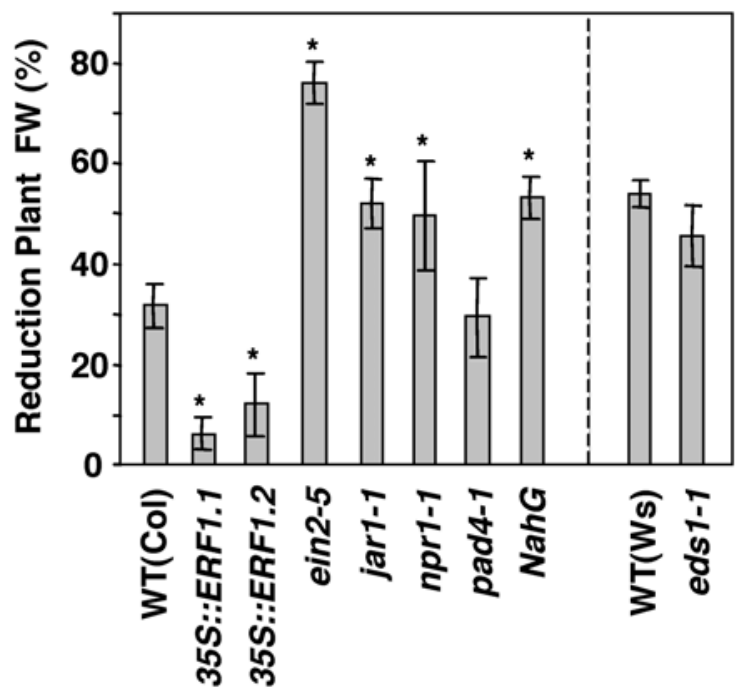

Fig. 3. Plant fresh weight $(\mathrm{FW})$ reduction $(\%$; average \pm standard deviation) and disease symptoms caused by Fusarium oxysporum f. sp. lycopersici. A, FW reduction in wild-type (WT) (Col-0 and Ws-0), transgenic lines $35 S:: E R F 1.1$ and $35 S:: E R F 1.2$, and mutants ein2-5, jar11, npr1-1, pad4-1, NahG, and eds1-1 (Ws-0 background), 10 days after inoculation with $5 \times 10^{5}$ spores $/ \mathrm{ml}$. Asterisks indicate data significantly different from the corresponding WT data set $(P>0.95, t$ test $)$. plants from WT (ecotypes Col-0 and Ws-0) and mutants impaired in the ET (ein2-5), JA (jarl-1), or SA (NahG, nprl-1, pad4-1, and eds1-1) signaling were challenged with a spore suspension of $F$. oxysporum f. sp. conglutinans or $F$. oxysporum $\mathrm{f}$. sp. lycopersici and the reduction of the plant $\mathrm{FW}$ caused by the fungus was determined after 10 days. Mutations that disrupt the ET (ein2-5), JA (jarl-1), or SA (NahG and nprl-1) signal transduction pathways increased plant susceptibility to both fungi, because $\mathrm{FW}$ reduction in the mutants (58 to $80 \%$ ) was significantly higher than that of the WT plants ( $42 \%$ for $F$. oxysporum $\mathrm{f}$. sp. conglutinans and $32 \%$ for $F$. oxysporum f. sp. lycopersici) (Figs. 2A and 3). In contrast, mutations in the PAD4 and EDS1 genes, which promote SA accumulation and are required for activation of resistance mediated by TIR-NBS-LRR genes, did not affect susceptibility (Figs. 2A and 3). The percentage of inoculated plants that decayed 10 days after inoculation was higher in the ein2-5, jarl-1, NahG, and nprl-1 mutants than in the WT plants (data not shown). Moreover, disease symptoms and necrotic cells revealed by trypan blue staining were more severe and abundant, respectively, in the susceptible mutants (e.g., NahG) than in WT plants (Fig. 2B and $\mathrm{C}$ and data not shown). These results suggest that Arabidopsis resistance to $F$. oxysporum is ET, JA, and SA dependent, and PAD4 and EDS1 independent.

$N a h G$ plants, which are defective in SA accumulation, have been shown to be impaired also in nonhost resistance, probably as a secondary effect of the conversion of SA to catechol (Glazebrook et al. 2003; van Wees and Glazebrook 2003). To confirm the function of SA signaling in Arabidopsis resistance to $F$. oxysporum fungi, because this pathway has not been implicated previously in defense against soilborne fungi, we tested the resistance to $F$. oxysporum of additional SA-defective mutants, such as sid2-1 and eds5-1, which are impaired in SA accumulation (Nawrath et al. 2002; Nawrath and Métraux 1999; Wildermuth et al. 2001), and pad2-1 (Glazebrook and Ausubel 1994; Glazebrook et al. 2003). Ten-day-old plants from WT, mutants sid2-1, eds5-1, and pad2-1, and mutants pad4-1 and

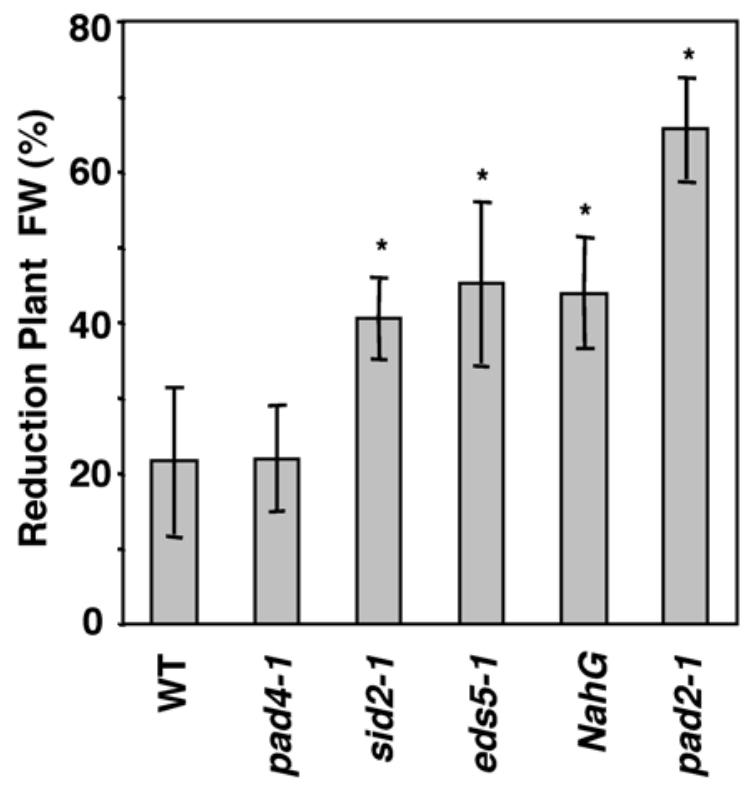

Fig. 4. Plant fresh weight (FW) reduction (\%; average \pm standard deviation) caused by Fusarium oxysporum f. sp. conglutinans in wild-type (WT) plants and the salicylic acid-defective mutants sid2-1, eds5-1, $N a h G$, pad4-1, and pad2-1, 8 days after inoculation with $5 \times 10^{5}$ spores $/ \mathrm{ml}$. Asterisks indicate data significantly different from the corresponding WT data set $(P>0.95, t$ test $)$ 
$N a h G$ plants, included in the experiment for comparison, were inoculated with a spore suspension of $F$. oxysporum f. sp. conglutinans or $F$. oxysporum f. sp. lycopersici and the reduction plant FW caused by the fungus was determined 8 to 10 days later. FW reduction caused by $F$. oxysporum f. sp. conglutinans in mutants sid2-1, eds5-1, and pad2-1 was similar to that observed in $N a h G$ plants, and significantly higher than that of the WT plants and pad4-1 mutant (Fig. 4). Similar results were obtained with $F$. oxysporum f. sp. lycopersici (data not shown). These data confirmed that Arabidopsis resistance to F. oxysporum is SA dependent and PAD4 independent. Although cooperation between ET, JA, and SA is required for Arabidopsis resistance to the two $F$. oxysporum fungi, activation of the ET and the JA pathways by ERF1 overexpression is sufficient to confer enhanced resistance to them.

\section{DISCUSSION}

The EREBP transcriptional factor ERF1 has been proposed to regulate Arabidopsis resistance to the necrotrophic fungi $B$. cinerea and $P$. cucumerina by integrating ET and JA defense responses (Berrocal-Lobo et al. 2002a; Lorenzo et al. 2003). Consistent with this hypothesis, comparative analysis of the transcriptome of $35 S:: E R F 1$ plants with that of WT plants treated simultaneously with ET and JA has revealed that ERF1 regulates the expression of a large number of ET and JA responsive defense-related genes (Lorenzo et al. 2003). The observations that ERF1 is induced upon infection with $F$. oxysporum f. sp. conglutinans, $P$. syringae pv. maculicola ES4326, and B. cinerea, and that these responses are ET and JA dependent and SA independent (this article; Berrocal-Lobo et al. 2002a; Chen et al. 2002; M. Berrocal-Lobo and A. Molina, unpublished results) are in line with the proposed defensive function of ERF1. The SA-independent regulation of ERF 1 by pathogens is supported by the data presented here showing that ERF1 induction by $F$. oxysporum f. sp. conglutinans does not depend on the SA-signaling regulators EDS1 and NPR1, or on PAD4, which has been proposed to be a putative repressor of the $\mathrm{SA}$-induced expression of the ERF1 gene (Oñate-Sánchez and Singh 2002).

The enhanced resistance to $F$. oxysporum f. sp. conglutinans and f. sp. lycopersici mediated by ERF1 overexpression (Figs. 2 and 3) is consistent with that mediated in Arabidopsis by the ERF1-related factor PTI4 against Erysiphe orontii and Pseudomonas syringae pv. tomato (Gu et al. 2002), and that shown by transgenic tobacco plants overexpressing the EREBP factor TSI1 against $P$. syringae pv. tabaci (Park et al. 2001). Altogether, these observations indicate that EREBP transcriptional factors, which have been linked to a wide range of stress responses (e.g., cold and drought) (Singh et al. 2002), also have a relevant function in the regulation of plant resistance to pathogens.

The enhanced resistance of ERF1 transgenic plants to $F$. oxysporum (this article), Plectosphaerella cucumerina, and B. cinerea (Berrocal-Lobo et al. 2002a) may be the result of the constitutive accumulation at high concentration of different antifungal compounds in the 35S:ERF1 plants. Among the genes upregulated in these plants are several that encode antifungal proteins (e.g., defensins and PR proteins) and enzymes involved in the synthesis and activation of indole glucosinolates (Lorenzo et al. 2003). Glucosinolates have been directly implicated in Arabidopsis resistance to F. oxysporum f. sp. matthiolae (Tierens et al. 2001). Additionally, indole glucosinolates and defensins have direct antimicrobial activity in vitro against $P$. cucumerina and $F$. oxysporum, and defensins also inhibit $B$. cinerea (Berrocal-Lobo et al. 2002b; Thevissen et al. 1999; Tierens et al. 2001).
Although vascular wilt caused by $F$. oxysporum fungi is an economically important disease, the molecular and genetic basis of plant resistance to these fungi remain poorly understood. Gene-for-gene resistance has been described in the interaction between $F$. oxysporum and tomato and muskmelon plants (Simons et al. 1998), whereas monogenic resistance has not been identified in other $F$. oxysporum-plant interactions. We have analyzed the resistance of 40 Arabidopsis accessions to $F$. oxysporum $\mathrm{f}$. sp. conglutinans and no fully resistant accessions have been found (F. Llorente, C. Alonso-Blanco, and A. Molina, unpublished results). These results are in line with the observation of Urban and associates (2002) concerning Arabidopsis resistance to the ear blight causing agents $F$. graminearum and $F$. culmorum.

Using Arabidopsis signaling-defective mutants, we have provided evidence for components of a signal transduction network that controls resistance to $F$. oxysporum soilborne fungi and have proposed a model that is consistent with our results (Fig. 5). Resistance to these fungi requires ET, JA, and SA defense responses because mutants (ein2-5, jarl-1, NahG, nprl-1, sid21 , eds5-1, and pad2-1) impaired in these signaling pathways are more susceptible than WT plants to two F. oxysporum isolates. Involvement of the ET and JA pathways in resistance to soilborne fungi and oomycetes has been described previously: both are required for Arabidopsis resistance to several Pythium spp. fungi, and ET signaling is needed for an effective resistance of tobacco to several soilborne fungi, including $F$. oxysporum and F. solani (Geraats et al. 2002; Staswick et al. 1998; Thomma et al. 1999, 1998; Tiryaki and Staswick 2002; Vijayan et al. 1998). Consistent with the proposed role of ET signaling in resistance to $F$. oxysporum fungi, we have observed that, among the mutants analyzed, ein2-5 was the most susceptible to the $F$. oxy-

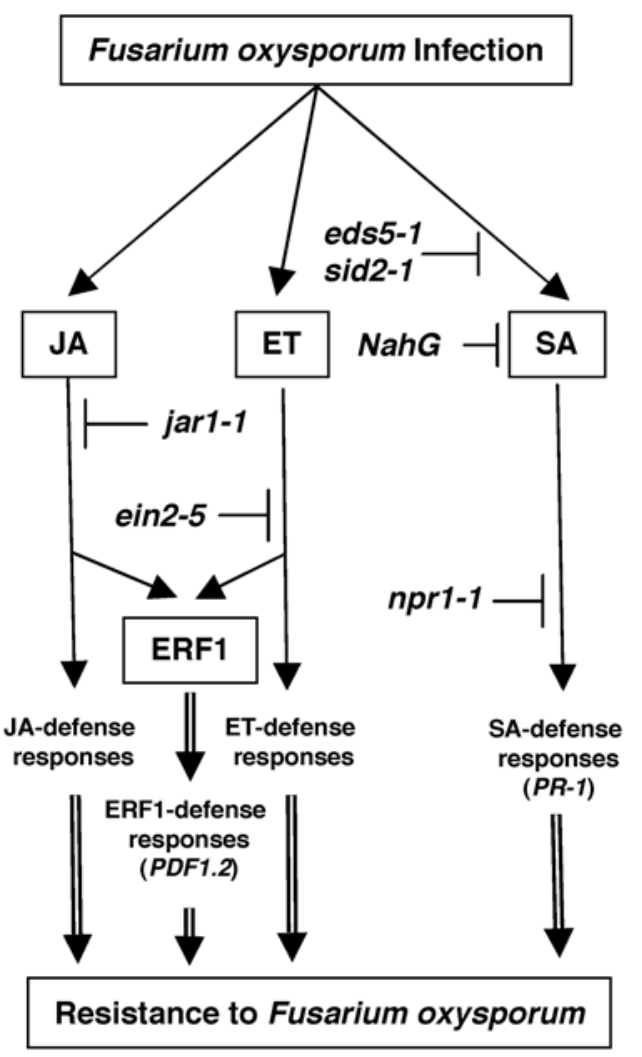

Fig. 5. Proposed model of the signal transduction network that controls Arabidopsis thaliana resistance to Fusarium oxysporum. Mutants impaired in resistance to this fungus are shown. Ethylene (ET) and jasmonic acid (JA) defense responses dependent and independent of ethylene response factor 1 (ERF1) can be activated by the fungal infection. Arrows indicate activation and bars repression; $\mathrm{SA}=$ salicylic acid. 
sporum f. sp. lycopersici isolate that is less virulent on Arabidopsis than the $F$. oxysporum $\mathrm{f}$. sp. conglutinans isolate, and that the enhanced resistance of $35 S:: E R F 1$ plants to the $F$. oxysporum f. sp. lycopersici isolate was higher than that to the $F$. oxysporum f. sp. conglutinans isolate. In contrast, genetic evidence of the involvement of SA signaling in resistance to soilborne pathogens has not been described previously. Here, we demonstrate that this pathway is required for Arabidopsis resistance to F. oxysporum, because the SA-defective mutants $N a h G$, sid2-1, eds5-1, npr1-1, and pad2-1 show enhanced susceptibility phenotypes. Although SA signaling and the NPRI gene are required for resistance, mutations in the $E D S 1$ and $P A D 4$ genes, which act upstream of SA accumulation and are involved in activation of gene-for-gene resistance signal transduction mediated by the TIR-NBS-LRR gene subclass (Aarts et al. 1998; Falk et al. 1999; Jirage et al. 1999), do not have any significant effect on resistance to $\mathrm{F}$. oxysporum, which is consistent with the apparent lack of gene-for-gene resistance to this fungus ( $\mathrm{F}$. Llorente, C. Alonso-Blanco, and A. Molina, unpublished results).

Negative and positive interactions between the JA-ET and SA pathways in the regulation of plant defense responses have been described (Kunkel and Brooks 2002). SA and JA pathways seem to be mutually antagonistic, as deduced from the analysis of Arabidopsis mutants impaired in SA signaling, such as pad4 and nprl-1, which exhibit enhanced expression of JA-responsive genes (e.g., $P D F 1.2$ ) after JA treatment or pathogen infection (Glazebrook et al. 2003; Spoel et al. 2003). Furthermore, mutants impaired in JA signaling either constitutively express SA-mediated resistance (e.g., $m p k 4$ and ssi2) or show a hyperactivation of the SA response after Pseudomonas syringae infection (e.g., coil) (Glazebrook et al. 2003; Kachroo et al. 2001; Kloek et al. 2002; Petersen et al. 2000). Reciprocal inhibition between ET and SA signaling pathways is suggested by the elevated expression of SA-regulated genes (e.g., $P R-1$ ) in the ET-defective ein2 mutant (Glazebrook et al. 2003) and the enhanced susceptibility to $P$. syringae pv. tomato DC3000 of 35S::ERF1 Arabidopsis plants (Berrocal-Lobo et al. 2002a)

Despite these examples of negative interaction, the requirement of the three pathways for an effective resistance of Arabidopsis against $F$. oxysporum f. sp. conglutinans and $F$. oxysporum f. sp. lycopersici (this article), Plectosphaerella cucumerina (Berrocal-Lobo et al. 2002a), Pseudomonas syringae, and Peronospora parasitica (Clarke et al. 2000), and for local resistance to B. cinerea (Ferrari et al. 2003), are clear examples of positive cooperation. Furthermore, microarray analysis of the gene expression pattern of Arabidopsis plants after treatment with ET, JA, or SA or upon pathogen infection have demonstrated that responses regulated by these hormones mostly overlap (Glazebrook et al. 2003; Schenk et al. 2000).

\section{MATERIALS AND METHODS}

\section{Biological materials and growth conditions.}

The Arabidopsis thaliana WT mutants and transgenic plants used throughout this study were in Columbia (Col-0) background except for the eds1-1 mutant, which was in Wassilewskija (Ws-0) background. Mutants jarl-1 (Staswick et al. 1998), ein2-5 (Guzmán and Ecker 1990), pad4-1 (Jirage et al. 1999), and pad2-1 (Glazebrook and Ausubel 1994) were obtained from the Nottingham Arabidopsis Stock Center. NahG transgenic plants (Delaney et al. 1994) and the nprl-1 (Cao et al. 1997), coil-1 (Feys et al. 1994), eds1-1 (Falk et al. 1999), and sid2-1 and eds5-1 (Nawrath and Métraux 1999) mutants were provided by J. Ryals (Syngenta Corp., Research Triangle Park, NC, U.S.A.), X. Dong (Duke University, Durham, NC, U.S.A.), J. Turner (University of East Anglia, Norwich, U.K.),
J. Parker (MPIZ, Cologne, Germany), and J.-P. Métraux (University of Fribourg, Switzerland), respectively. The generation and characterization of $35 S: \because E R F 1$ transgenic lines, which were the gift of R. Solano (Centro Nacional Biotecnología, Madrid, Spain), have been described previously (Solano et al. 1998). The fungal pathogens $F$. oxysporum f. sp. conglutinans (isolate 699) and F. oxysporum f. sp. lycopersici (isolate 42-87) were provided by M. I. G. Roncero (Universidad de Córdoba, Spain). The fungus Plectosphaerella cucumerina was the gift of B. Mauch-Mani (University of Neuchâtel, Switzerland).

Seed from plants were surface sterilized, sown either on soil or on square petri dishes containing MS medium (Duchefa, Haarlem, The Netherlands) with $0,8 \%$ bactoagar (DB, Sparks, MD, U.S.A.), transferred to a phytochamber, and grown as described previously (Berrocal-Lobo et al. 2002a). The coil-1 plants used were selected on plates containing $50 \mu \mathrm{M}$ JA (Feys et al. 1994) and the JA-resistant plants were transferred to soil or MS plates.

F. oxysporum f. sp. conglutinans and $F$. oxysporum f. sp. lycopersici were grown on liquid potato dextrose broth medium (Difco Laboratories, Detroit) at $28^{\circ} \mathrm{C}$ for 5 days under shaking $(100 \mathrm{rpm})$, and then the spores were collected by centrifugation and stored at $-80^{\circ} \mathrm{C}$ in $30 \%$ glycerol. Spores from $P$. cucumerina and $B$. cinerea were obtained as described previously (Berrocal-Lobo et al. 2002a).

\section{Plant infection with pathogens.}

Arabidopsis infection with $F$. oxysporum f. sp. conglutinans and $F$. oxysporum f. sp. lycopersici was done by spraying 10day-old plants from WT plants, mutants, and transgenic $35 S:: E R F 1$ plants, growing on square (12-by-12-cm) MS bactogar plates, with a spore suspension $\left(5 \times 10^{5}\right.$ spores $\left./ \mathrm{ml}\right)$ of the fungus ( $1.5 \mathrm{ml} /$ plate). Mock inoculations were done by spraying the plates with sterile water containing an amount of glycerol (final concentration $0.03 \%$ ) equivalent to the fungal spore suspension used for infection. Progression of the infection was followed macroscopically by viewing the disease symptoms. Ten days after inoculation, FW of individual inoculated and mock-inoculated plants was measured and the average reduction in plant FW ( \pm standard deviation) caused by the fungal infection was calculated as reduction (\%) plant $\mathrm{FW}=100 \times(1$ - FW of inoculated plant/average FW of mock-inoculated plants). Lactophenol trypan blue staining of mock-inoculated and inoculated plants was done as described (Keogh et al. 1980). At least 15 plants per genotype were inoculated in each experiment, which was repeated four times.

\section{Northern blot analysis.}

Plant total RNA was purified as described by Lagrimini and associates (1987). RNAs were subjected to electrophoresis on $1.5 \%$ formaldehyde/agarose gels and blotted to Hybond-N+ membranes (Amersham, U.K.). ERF1 probes were labeled with $100 \mu \mathrm{Ci}$ of $\alpha-{ }^{32} \mathrm{P}-\mathrm{dATP}$. All other probes were labeled with $50 \mu \mathrm{Ci}$ of $\alpha-{ }^{32} \mathrm{P}-\mathrm{dATP}$. All probes used and the hybridization conditions have been described previously (BerrocalLobo et al. 2002a). At least 12 plants per genotype were inoculated in each experiment for Northern blot analysis, and the experiment was repeated two times.

\section{ACKNOWLEDGMENTS}

This work was financed by the Ministerio de Ciencia y Tecnología from Spain (grant number BIO2000-1308 to A. Molina), Comunidad de Madrid (grant. number 07B/00002/2002 to A. Molina), and by the European Project BIOCT97-2120 (DGXII-SSMI grant to M. BerrocalLobo). We thank F. García-Olmedo and P. Rodríguez-Palenzuela for critical reading of the manuscript and stimulating discussion, and G. López and J. García for technical assistance. 


\section{LITERATURE CITED}

Aarts, N., Metz, M., Holub, E., Staskawicz, B. J., Daniels, M. J., and Parker, J. 1998. Different requirements for EDS1 and NDR1 by disease resistance genes define at least two $\mathrm{R}$ gene-mediated signaling pathways in Arabidopsis. Proc. Natl. Acad. Sci. U.S.A. 95:10306-10311.

Armstrong, G. M., and Armstrong, J. K. 1981. Formae speciales and races of Fusarium oxysporum causing wilt disease. Pages 391-399 in: Fusarium: Diseases, Biology, and Taxonomy. P. E. Nelson, T. A. Toussoun, and R. J. Cook, eds. Pennsylvania State University Press, University Park, U.S.A.

Asai, T., Stone, J. M., Heard, J. E., Kovtun, Y., Yorgey, P., Sheen, J., and Ausubel, F. M. 2000. Fumonisin B1-induced cell death in Arabidopsis protoplasts requires jasmonate-, ethylene-, and salicylate-dependent signaling pathways. Plant Cell 12:1823-36.

Beckman, C. H. 1987. The Nature of Wilt Disease of Plants. American Phytopathological Society, St. Paul, MN, U.S.A.

Berrocal-Lobo, M., Molina, A., and Solano, R. 2002a. Constitutive expression of ETHYLENE-RESPONSE-FACTOR1 in Arabidopsis confers resistance to several necrotrophic fungi. Plant J. 29:23-32.

Berrocal-Lobo, M., Segura, A., Moreno, M., Lopez, G., Garcia-Olmedo, F., and Molina, A. 2002b. Snakin-2, an antimicrobial peptide from potato whose gene is locally induced by wounding and responds to pathogen infection. Plant Physiol. 128:951-61.

Cao, H., Glazebrook, J., Clarke, J. D., Volko, S., and Dong, X. 1997. The Arabidopsis NPR1 gene that controls systemic acquired resistance encodes a novel protein containing ankyrin repeats. Cell 88:57-63

Chen, W., Provart, N. J., Glazebrook, J., Katagiri, F., Chang, H. S., Eulgem, T., Mauch, F., Luan, S., Zou, G., Whitham, S. A., Budworth, P. R., Tao, Y., Xie, Z., Chen, X., Lam, S., Kreps, J. A., Harper, J. F., Si-Ammour, A., Mauch-Mani, B., Heinlein, M., Kobayashi, K., Hohn, T., Dangl, J. L., Wang, X., and Zhu, T. 2002. Expression profile matrix of Arabidopsis transcription factor genes suggests their putative functions in response to environmental stresses. Plant Cell 14:559-74.

Clarke, J. D., Volko, S. M., Ledford, H., Ausubel, F. M., and Dong, X. 2000. Roles of salicylic acid, jasmonic acid, and ethylene in cprinduced resistance in Arabidopsis. Plant Cell 12:2175-2190.

Dangl, J. L., and Jones, J. D. 2001. Plant pathogens and integrated defence responses to infection. Nature 411:826-33

Delaney, T. P, Uknes, S., Vernooij, B., Friedrich, L., Weymann, K., Negrotto, D., Gaffney, T., Gut Rella, M., Kessmann, H., Ward, E., and Ryals, J. A. 1994. A central role of salicylic acid in plant disease resistance. Science 266:1247-1250.

Dempsey, D. A., Shah, J., and Klessig, D. F. 1999. Salicylic acid and disease resistance in plants. Crit. Rev. Plant Sci. 18:547-575.

Di Pietro, A., and Roncero, M. I. G. 1996. Endopolygalacturonase from Fusarium oxysporum f. sp. lycopersici: Purification, characterization, and production during infection of tomato plants. Phytopathology $86: 1324-1330$

Dong, X. 1998. SA, JA, ethylene, and disease resistance in plants. Curr. Opin. Plant Biol. 1:316-23.

Ellis, C., Karafyllidis, I., and Turner, J. G. 2002. Constitutive activation of jasmonate signaling in an Arabidopsis mutant correlates with enhanced resistance to Erysiphe cichoracearum, Pseudomonas syringae, and Myzus persicae. Mol. Plant-Microbe Interact. 15:1025-1030.

Falk, A., Feys, B. J., Frost, L. N., Jones, J. D., Daniels, M. J., and Parker, J. E. 1999. EDS1, an essential component of R gene-mediated disease resistance in Arabidopsis has homology to eukaryotic lipases. Proc. Natl. Acad. Sci. U.S.A. 96:3292-3297.

Fan, W., and Dong, X. 2002. In vivo interaction between NPR1 and transcription factor TGA2 leads to salicylic acid-mediated gene activation in Arabidopsis. Plant Cell 6:751-759.

Ferrari, S., Plotnikova, J. M., De Lorenzo, G., and Ausubel, F. M. 2003. Arabidopsis local resistance to Botrytis cinerea involves salicylic acid and camalexin and requires EDS4 and PAD2, but not SID2, EDS5 or PAD4. Plant J. 35:193-205.

Feys, B., Benedetti, C. E., Penfold, C. N., and Turner, J. G. 1994. Arabidopsis mutants selected for resistance to the phytotoxin coronatine are male sterile, insensitive to methyl jasmonate, and resistant to a bacterial pathogen. Plant Cell 6:751-759.

Geraats, B. P., Bakker, P. A., and van Loon, L. C. 2002. Ethylene insensitivity impairs resistance to soilborne pathogens in tobacco and Arabidopsis thaliana. Mol. Plant-Microbe Interact. 15:1078-1085.

Glazebrook, J. 2001. Genes controlling expression of defense responses in Arabidopsis-2001 status. Curr. Opin. Plant Biol. 4:301-308.

Glazebrook, J., and Ausubel, F. M. 1994. Isolation of phytoalexindeficient mutants of Arabidopsis thaliana and characterization of their interactions with bacterial pathogens. Proc. Natl. Acad. Sci. U.S.A. 91:8955-8959.
Glazebrook, J., Chen, W., Estes, B., Chang, H. S., Nawrath, C., Metraux J. P., Zhu, T., and Katagiri, F. 2003. Topology of the network integrating salicylate and jasmonate signal transduction derived from global expression phenotyping. Plant J. 34:217-228

Glazebrook, J., Zook, M., Mert, F., Kagan, I., Rogers, E. E., Crute, I. R., Holub, E. B., Hammerschmidt, R., and Ausubel, F. M. 1997. Phytoalexin-deficient mutants of Arabidopsis reveal that PAD4 encodes a regulatory factor and that four PAD genes contribute to downy mildew resistance. Genetics 146:381-392.

Gu, Y. Q., Wildermuth, M. C., Chakravarthy, S., Loh, Y. T., Yang, C., He, X., Han. Y., and Martin, G. B. 2002. Tomato transcription factors PTI4, PTI5, and PTI6 activate defense responses when expressed in Arabidopsis. Plant Cell 14:817-831.

Guzman, P., and Ecker, J. R. 1990. Exploiting the triple response of Arabidopsis to identify ethylene-related mutants. Plant Cell 2:513-523.

Hoffman, T., Schmidt, J. S., Zheng, X., and Bent, A. F. 1999. Isolation of ethylene-insensitive soybean mutants that are altered in pathogen susceptibility and gene-for-gene disease resistance. Plant Physiol. 119:935-950

Holt, B. F,. 3rd, Hubert, D. A., and Dangl, J. L. 2003. Resistance gene signaling in plants: complex similarities to animal innate immunity. Curr. Opin. Immunol. 15:20-25.

Jirage, D., Tootle, T. L., Reuber, T. L., Frost, L. N., Feys, B. J., Parker, J. E., Ausubel, F. M., and Glazebrook, J. 1999. Arabidopsis thaliana $P A D 4$ encodes a lipase-like gene that is important for salicylic acid signaling. Proc. Natl. Acad. Sci. U.S.A. 96:13583-13588.

Kachroo, P., Shanklin, J., Shah, J., Whittle, E. J., and Klessig, D. F. 2001. A fatty acid desaturase modulates the activation of defense signaling pathways in plants. Proc. Natl. Acad. Sci. U.S.A. 98:9448-9453.

Keogh, R. C., Deverall, B. J., and McLeod, S. 1980. Comparison of histological and physiological responses to Phakopsora pachyrhizi in resistant and susceptible soybean. Trans. Br. Mycol. Soc. 74:329-333.

Kloek, A. P., Verbsky, M. L., Sharma, S. B., Schoelz, J. E., Vogel, J., Klessig, D. F., and Kunkel, B. N. 2002. Resistance to Pseudomonas syringae conferred by an Arabidopsis thaliana coronatine-insensitive (coil) mutation occurs through two distinct mechanisms. Plant J. 26:509-522.

Knoester, M., van Loon, L. C., van den Heuvel, J., Hennig, J., Bol, J. F., and Linthorst, H. J. M. 1998. Ethylene-insensitive tobacco lacks nonhost resistance against soil-borne fungi. Proc. Natl. Acad. Sci. U.S.A. 95:1933-1937.

Kunkel, B. N., and Brooks, D. M. 2002. Cross talk between signaling pathways in pathogen defense. Curr. Opin. Plant Biol. 5:325-331.

Lagrimini, L. M., Burkhart, W., Moyer, M., and Rothstein, S. 1987. Molecular cloning of complementary DNA encoding the ligninforming peroxidase from tobacco: molecular analysis and tissuespecific expression. Proc. Natl. Acad. Sci. U.S.A. 84:7542-7546.

Lorenzo, O., Piqueras, R., Sánchez-Serrano, J. J., and Solano, R. 2003. ETHYLENE RESPONSE FACTOR1 integrates signals from ethylene and jasmonate pathways in plant defense. Plant Cell 15:165-178

Mauch-Mani, B., and Slusarenko, A. J. 1994. Systemic acquired resistance in Arabidopsis thaliana induced by predisposing infection with a pathogenic isolate of Fusarium oxysporum. Mol. Plant-Microbe Interact. 7:378-383.

Nawrath, C., and Metraux, J. P. 1999. Salicylic acid induction-deficient mutants of Arabidopsis express $P R-2$ and $P R-5$ and accumulate high levels of camalexin after pathogen inoculation. Plant Cell 11:13931404

Nawrath, C., Heck, S., Parinthawong, N., and Metraux, J. P. 2002. EDS5, an essential component of salicylic acid-dependent signaling for disease resistance in Arabidopsis, is a member of the MATE transporter family. Plant Cell 14:275-286.

Norman-Setterblad, C., Vidal, S., and Palva, E. T. 2000. Interacting signal pathways control defense gene expression in Arabidopsis in response to cell wall-degrading enzymes from Erwinia carotovora. Mol. PlantMicrobe Interact. 13:430-438.

Nürnberger, T., and Scheel, D. 2001. Signal transmission in the plant immune response. Trends Plant Sci. 6:372-379.

Oñate-Sánchez, L., and Singh, K. B. 2002. Identification of Arabidopsis ethylene-responsive element binding factors with distinct induction kinetics after pathogen infection. Plant Physiol. 128:1313-1322.

Park, J. M., Park, C. J., Lee, S. B., Ham, B. K., Shin, R., and Paek, K. H. 2001. Overexpression of the tobacco Tsi1 gene encoding an EREBP/ AP2-type transcription factor enhances resistance against pathogen attack and osmotic stress in tobacco. Plant Cell 13:1035-1046

Penninckx, I. A., Eggermont, K., Terras, F. R., Thomma, B. P., De Samblanx, G. W., Buchala, A., Metraux, J. P., Manners, J. M., and Broekaert, W. F. 1996. Pathogen-induced systemic activation of a plant defensin gene in Arabidopsis follows a salicylic acid-independent pathway. Plant Cell 8:2309-2323. 
Petersen, M. Brodersen, P., Naested, H., Andreasson, E., Lindhart, U., Johansen, B., Nielsen, H. B., Lacy, M., Austin, M. J., Parker, J. E., Sharma, S. B., Klessig, D., Martienssen, R., Matteson, O., Jensen, A. B., and Mundy, J. 2000. Arabidopsis map kinase 4 negatively regulates systemic acquired resistance. Cell 103:1111-1120.

Pieterse, C. M., van Wees, S. C., van Pelt, J. A., Knoester, M., Laan, R., Gerrits, H., Weisbeek, P. J., and van Loon, L. C. 1998. A novel signaling pathway controlling induced systemic resistance in Arabidopsis. Plant Cell 10:1571-1580

Pieterse, C. M., and van Loon, L. C. 1999. Salicylic acid-independent plant defence pathways. Trends Plant Sci. 4:52-58.

Ryals, J. A., Neuenschwander, U. H., Willits, M. G., Molina, A., Steiner, H.-Y., and Hunt, M. D. 1996. Systemic acquired resistance. Plant Cell 8:1809-1819

Ryals, J., Weymann, K., Lawton, K., Friedrich, L., Ellis, D., Steiner, H.Y., Johnson, J., Delaney, T. P., Jesse, T., Vos, P., and Uknes, S. 1997. The Arabidopsis NIM1 protein shows homology to the mammalian transcription factor inhibitor IкB. Plant Cell 9:425-439.

Schenk, P. M., Kazan, K., Wilson, I., Anderson, J. P., Richmond, T., Somerville, S. C., and Manners, J. M. 2000. Coordinated plant defense responses in Arabidopsis revealed by microarray analysis. Proc. Natl. Acad. Sci. U.S.A. 97:11655-11660.

Simons, G., Groenendijk, J., Wijbrandi, J., Reijans, M., Groenen, J., Diergaarde, P., Van der Lee, T., Bleeker, M., Onstenk, J., de Both, M., Haring, M., Mes, J., Cornelissen, B., Zabeau, M., and Vos, P. 1998. Dissection of the Fusarium 12 gene cluster in tomato reveals six homologs and one active gene copy. Plant Cell 10:1055-1068.

Singh, K., Foley, R. C., and Oñate-Sánchez, L. 2002. Transcription factors in plant defense and stress responses. Curr. Opin. Plant Biol. 5:430-436.

Solano, R., Stepanova, A., Chao, Q., and Ecker, J. R. 1998. Nuclear events in ethylene signaling: a transcriptional cascade mediated by ETHYLENE-INSENSITIVE3 and ETHYLENE-RESPONSEFACTOR1. Genes Dev. 12:3703-3714.

Spoel, S. H., Koornneef, A., Claessens, S. M., Korzelius, J. P., Van Pelt, J. A., Mueller, M. J., Buchala, A. J., Metraux, J. P., Brown, R., Kazan, K., Van Loon, L. C., Dong, X., and Pieterse, C. M. 2003. NPR1 modulates cross-talk between salicylate- and jasmonate-dependent defense pathways through a novel function in the cytosol. Plan Cell 15:760770 .

Staswick, P. E., Yuen, G. Y., and Lehman, C. C. 1998. Jasmonate signaling mutants of Arabidopsis are susceptible to the soil fungus Pythium irregulare. Plant J. 15:747-754.

Stone, J. M., Heard, J. E., Asai, T., and Ausubel, F. M. 2000. Simulation of fungal-mediated cell death by fumonisin $\mathrm{B} 1$ and selection of fumonisin B1-resistant ( $f b r)$ Arabidopsis mutants. Plant Cell 12:1811-1822.

Thevissen, K., Terras, F. R., and Broekaert, W. F. 1999. Permeabilization of fungal membranes by plant defensins inhibits fungal growth. Appl. Environ. Microbiol. 65:5451-5458.

Thomma, B. P., Eggermont, K., Tierens, K. F. M. J., and Broekaert, W. F 1999. Requirement of functional ethylene-insensitive 2 gene for efficient resistance of Arabidopsis to infection by Botrytis cinerea. Plant Physiol. 121:1093-1101.

Thomma, B. P., Eggermont, K., Broekaert, W., and Cammue, B. P. A 2000. Disease development of several fungi on Arabidopsis can be reduced by treatment with methyl jasmonate. Plant Physiol. Biochem. 38:421-427.

Thomma, B. P., Penninckx, I. A., Broekaert, W. F., and Cammue, B. P. 2001. The complexity of disease signaling in Arabidopsis. Curr. Opin Immunol. 13:63-68

Thomma, B. P. H. J., Eggermont, K., Pennickx, I. A. M. A., Mauch-Mani, B., Vogelsang, R., Cammue, B. P. A., and Broekaert, W. F. 1998 Separate jasmonate-dependent and salicylate-dependent defenseresponse pathways in Arabidopsis are essential for resistance to distinct microbial pathogens. Proc. Natl. Acad. Sci. U.S.A. 95:15107-15111.

Tierens, K. F., Thomma, B. P., Brouwer, M., Schmidt, J., Kistner, K., Porzel, A., Mauch-Mani, B., Cammue, B. P., and Broekaert, W. F. 2001. Study of the role of antimicrobial glucosinolate-derived isothiocyanates in resistance of Arabidopsis to microbial pathogens. Plant Physiol. 125:1688-1699.

Tiryaki, I., and Staswick, P. E. 2002. An Arabidopsis mutant defective in jasmonate response is allelic to the auxin-signaling mutant axrl. Plant Physiol. 130:887-894.

Turner, J. G., Ellis, C., and Devoto, A. 2002. The jasmonate signal pathway. Plant Cell 14 (Suppl.):S153-S164.

Urban, M., Daniels, S., Mott, E., and Hammond-Kosack, K. 2002. Arabidopsis is susceptible to the cereal ear blight fungal pathogen Fusarium graminearum and Fusarium culmorum. Plant J. 32:961-973.

van Wees, S. C., and Glazebrook, J. 2003. Loss of non-host resistance of Arabidopsis NahG to Pseudomonas syringae pv. phaseolicola is due to degradation products of salicylic acid. Plant J. 33:733-742.

Vijayan, P., Shockey, J., Levesque, C. A., Cook, R. J., and Browse, J. 1998. A role for jasmonate in pathogen defense of Arabidopsis. Proc. Natl. Acad. Sci. U.S.A. 95:7209-7214.

Wang, K. L., Li, H., and Ecker, J. R. 2002. Ethylene biosynthesis and signaling networks. Plant Cell 14 (Suppl.):S131-S151

Wildermuth, M. C., Dewdney, J., Wu, G., and Ausubel, F. M. 2001. Isochorismate synthase is required to synthesize salicylic acid for plant defence. Nature 414:562-565.

Xu, Y., Chang, P., Liu, D., Narasimhan, M. L., Raghothama, K. G., Hasegawa, P. M., and Bressan, R. A. 1994. Plant defense genes are synergistically induced by ethylene and methyl jasmonate. Plant Cell 6:1077-1085. 